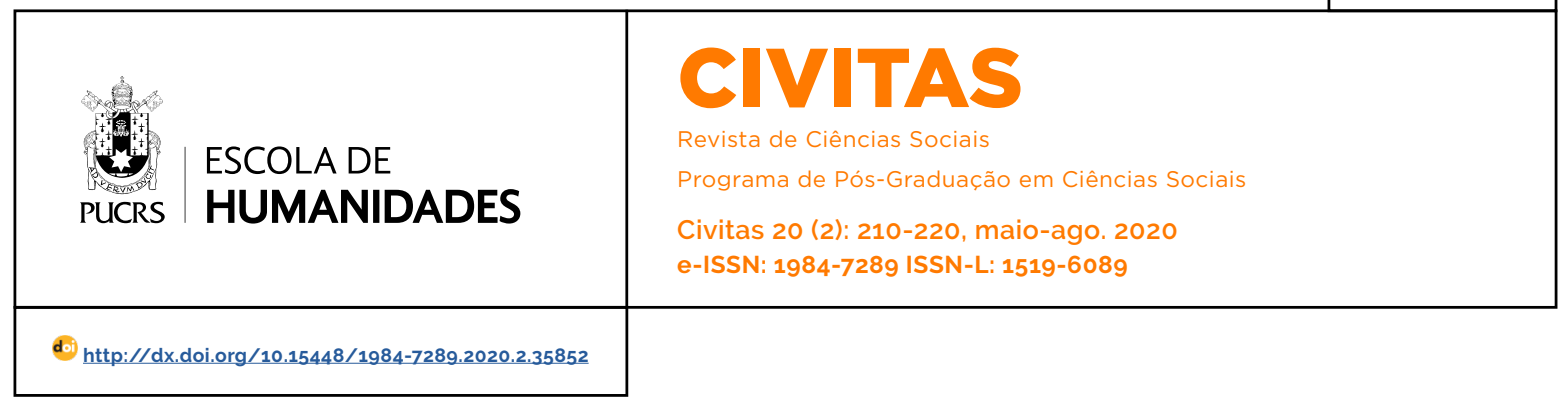

DOSSIÊ: MEIO-AMBIENTE EM DISPUTA

\title{
Representações e discursos sobre Amazônia na arte contemporânea: análise da cobertura jornalística sobre o trabalho dos artistas-xamãs
}

\author{
Representations and discourses on Amazon in contemporary art: analisys about the \\ journalistic coverage of the work of artists shamans
}

Representaciones y discursos sobre la Amazonía en el arte contemporáneo: análisis de la cobertura periodistica sobre el trabajo de los artistas chamanes

\section{Daniela Cordovil ${ }^{1}$}

orcid.org/0000-0002-3896-1072

daniela.cordovil@gmail.com

Recebido em: 30 set. 2019

Aprovado em: 18 mar. 2020. Publicado em: 4 ago. 2020

\section{(c) (1)}

Artigo está licenciado sob forma de uma licença Creative Commons Atribuição 4.0 Internacional.
Resumo: Este artigo se propõe a refletir sobre as representações em torno da Amazônia na cobertura midiática sobre projetos artísticos contemporâneos de Bené Fonteles e Ernesto Neto, a partir da forma como obras e artistas têm sido onoticiados pela mídia. Analisa-se como entrelaçam-se temas como ecologia, meio ambiente e xamanismo em exposições e no trabalho artístico de artistas brasileiros e amazônicos, e qual a recepção desses temas no circuito da arte contemporânea, a partir de uma análise sobre como essas obras são noticiadas pela mídia. A pesquisa discute as principais categorias mobilizadas pelo discurso midiático para noticiar a repercussão desses trabalhos artísticos e quais os referenciais simbólicos associados à Amazônia presentes nesses discursos. Palavras-chave: Amazônia. Xamanismo. Arte contemporânea. Midia. Ecologia.

Abstract: This paper discuss how Amazon is portraited in Brazilian contemporary art, by analising how two artists, Bené Fonteles and Ernesto Neto, who use Amazon and indigenous people as a source of inspiration for their work have been reported by the media. It analyzes how ecology, environment and shamanism are mobilized in exhibitions and in the artistic work of Brazilian and Amazonian artists, and the reception of these themes in the circuit of contemporary art. The research discusses the main categories mobilized by the media to report the repercussion of these artistic works and which are the symbolic references associated with Amazon present in these discourses.

Keywords: Amazon. Shamanism. Contemporary art. Media. Ecology.

Resumen: Este artículo reflexiona sobre las representaciones en torno a la Amazonía en la cobertura mediática de proyectos artísticos contemporáneos de Bené Fonteles y Ernesto Neto, en función de la forma en que los medios de comunicación han informado sobre obras y artistas. Analiza cómo temas como la ecología, el medio ambiente y el chamanismo se entrelazan en exposiciones y en el trabajo artístico de artistas brasileños y amazónicos, y la recepción de estos temas en el circuito de arte contemporáneo, a partir de un análisis de cómo se representan estas obras en los medios de comunicación. La investigación discute las principales categorías movilizadas por el discurso de los medios de comunicación para informar la repercusión de estas obras artísticas y cuáles son las referencias simbólicas asociadas con la Amazonía presentes en estos discursos. Palabras clave: Amazonia. Chamanismo. Arte contemporaneo. Medios de comunicación. Ecología 


\section{Introdução²}

Este artigo propõe-se a refletir sobre as representações da Amazônia na cobertura jornalistica sobre projetos artísticos contemporâneos, a partir da forma como obras e artistas têm sido noticiados pela mídia. Pretende-se discutir como entrelaçam-se temas como ecologia, meio ambiente e xamanismo, em exposições e no trabalho artístico de artistas brasileiros e amazônicos, e como a mídia retrata a recepção destes temas no circuito da arte contemporânea. Será dada especial atenção ao trabalho do artista plástico carioca Ernesto Neto produzido a partir da colaboração com os indigenas Huni Kuin, e do paraense Bené Fonteles. Ambos artistas possuem inspiração em temas amazônicos. Suas obras remetem a um imaginário e a uma estética ambientada no contexto da região, o que tem atraído a atenção de críticos no cenário nacional e internacional. ${ }^{3}$

Foram analisadas cinco matérias jornalísticas publicadas entre 2016 e 2018, em jornais e revistas de grande circulação. Uma delas foi publicada pelo jornal O Estado de S. Paulo, outra pela Folha de S. Paulo, duas foram publicadas no portal Casacor, da editora abril, e a outra foi publicada pela Revista Época, na sessão negócios. O destaque dado pela mídia a estas temáticas, assim como sua veiculação em grandes jornais brasileiros demonstra o interesse social despertado pelo tema, inclusive pelo seu potencial econômico. Neste sentido, as representações da Amazônia em obras de arte contemporânea ganham espaço na mídia por meio de um discurso que coincide com a proposta desses artistas, de dialogar com a alteridade dos povos indígenas.

Pretende-se nesta pesquisa elucidar alguns dos contextos políticos e simbólicos onde inserem-se tais discursos midiáticos a respeito do trabalho desses artistas sobre a Amazônia. Observa-se que a valorização da Amazônia e da figura do xamã na cobertura jornalistica sobre arte contemporânea surgem ancoradas em um contexto de ressignificação dos discursos de proteção da natureza e da ecologia, a partir de propostas de redescoberta dos universos mágicos e mitológicos como crítica aos paradigmas cientificistas e tecnocratas da ciência e sociedade contemporâneas.

Essas propostas também surgem na esteira de uma aproximação dos artistas ao pensamento de antropólogos e pesquisadores que identificam na Amazônia a solução para uma crise da ciência e da sociedade atual. No meio artístico, o debate sobre esta crise se dá a partir de propositura de alternativas estéticas que resgatem cosmovisões e ontologias não ocidentais, dai o interesse pela estética e cosmologia amerindia, presente nesses trabalhos.

A arte politica tem se tornado mais presente no cenário da arte contemporânea após 1990 (Bishop 2006). Apesar da crítica endereçada aos museus e à própria obra de arte enquanto agente transformador da sociedade, a concepção de uma arte engajada e atuante na construção de debates políticos tem ganhado força, especialmente na segunda década do século 21. Consonante com a virada conceitual na concepção a respeito da arte e da prática museal pós-1968, os museus têm buscado transformar-se em espaços de construção coletiva, ao promover um resgate e ressignificação do papel da arte por meio de um repensar da ligação entre arte e vida:

O processo de ruptura com os museus como
bastiões da alta cultura que passam a se abrir
para o grande público e, fazendo uso do discur-
so crítico das vanguardas, passam a colocar em
xeque critérios estabelecidos pela autonomia
da arte ocupa, com efeito, grande parte das
reflexões sobre instituições museais na con-
temporaneidade. Iniciado nos idos dos anos
1960 e levado a efeito a partir dos anos 1970,
o processo se deu também no Brasil e parece
vir realmente tendo efetividade no mundo da
vida contemporânea. (Sant'ana, Marcondes e
Miranda 2017, 830)
Miranda 2017, 830)

\footnotetext{
2 Investigação desenvolvida com apoio financeiro da Fundação para Ciência e Tecnologia de Portugal - FCT, por meio da bolsa PD/ $\mathrm{BD} / 142843 / 2018$

3 Bienal. 2016a. Agenda da 32. ${ }^{a}$ Bienal de São Paulo. Acessado em 10 jun. 2018, http://www.bienal.org.br/agenda/2725.
} 
No contexto de acentuação do caráter político da arte, têm sido bem aceitos no circuito das galerias, bienais e museus trabalhos de artistas que problematizam questões ecológicas e de ativismo político em prol dos povos da floresta. Este tipo de trabalho costuma trazer um diferencial artístico ao propor que o público vivencie experiências performáticas em ambientes imersivos. Usualmente, o propósito declarado de artistas e curadores ao propor tais experiências é construir uma empatia do público para com os modos de vida de povos indígenas ou caboclos, a exemplo do que se vê nos materiais educativos produzidos para a $32^{\mathrm{a}}$ Bienal de São Paulo. ${ }^{4}$ Esse caráter ativista e imersivo da arte que remete às culturas e povos amazônicos tem sido vastamente noticiado pela mídia, como veremos a partir da exposição de uma sintese da carreira e da cobertura jornalistica de trabalhos recentes dos dois artistas plásticos escolhidos para esta análise.

\section{Os artistas e as obras}

Bené Fonteles, que nasceu em Bragança, Pará, em 1953, conta com uma longa trajetória nas artes plásticas. Desde a década de 1970 suas obras integram exposições da Bienal de Arte de São Paulo. Seu trabalho estabelece um diálogo com as culturas indígenas, pelos quais também possui uma militância.

Em 2016 foi convidado para estar entre os artistas que compõem a $32^{a}$ Bienal de São Paulo, com o tema Incerteza viva. A Bienal de São Paulo, uma das mais tradicionais exposições de arte da América Latina, tem mostrado em suas últimas edições uma virada proposital no sentido da arte política. No bojo dos protestos ocorridos em 2013.

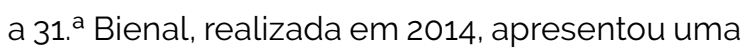
proposta de construção utópica fundamentada em intervenção política e engajamento social:

De acordo com análise qualitativa em etnografia da exposição e análise do catálogo da mostra, mais de $50 \%$ das obras exibidas faziam referência explícita a temas presentes no domínio da negociação política da esfera pública. Os conflitos que envolvem racismo, machismo, gentrificação e homofobia estão entre as práticas sociais questionadas por meio dos trabalhos apresentados. Do mesmo modo, muitas das demandas sociais apresentadas pelos manifestantes de junho de 2013 também serviram de inspiração para os debates estético-políticos da $31^{a}$ Bienal. (Sant'ana, Marcondes e Miranda 2017, 834)

Essa linha curatorial continua na Bienal de 2016, onde o tema Incerteza viva, volta a tratar de lutas políticas e utopias contemporâneas. Centrada nos debates ecológicos e nas inquietações sobre o futuro da vida no planeta, a exposição também discutiu questões do contemporâneo como a diversidade social e cultural. A exposição dialoga e expande alguns temas já tratados na Bienal de 2014, especialmente o do engajamento e complementaridade entre arte e política e o da utilização de linguagens artísticas para construção de novas formas de ativismo.

Para os curadores da Bienal, os temas da incerteza e do indizivel também pode ser lido sob uma perspectiva menos política e mais mística, como o indicam as inúmeras referências a noções retiradas do universo religioso - como "magia", "encantamento", "alquimia", "animismo" e "xamanismo" -, presentes nos discursos de artistas e curadores. Como argumenta Claudia Linhares na sua tese sobre magia e arte, o discurso curatorial presente nas duas últimas bienais de São Paulo tangenciou implicitamente as questões da magia. Segundo a autora, o resultado foi "uma bienal sobre 'coisas que não existem', e faltou pouco para que se falasse abertamente de magia" (Linhares 2018, 81). Ela demonstrou e analisou inclusive algumas das referências retiradas do pensamento mágico e místico, em especial da obra de Giordano Bruno, que influenciaram a concepção da $31^{\text {a }}$ Bienal, em 2014

Na Bienal de 2016, esses temas podem também ser facilmente identificados. No caderno educativo intitulado Cosmologia e incerteza, a

\footnotetext{
4 Volz, Jochen e Valquíria Prates. 2016. Incerteza viva: processos artísticos e pedagógicos da 32. Bienal de São Paulo. Cadernos Educativos da $32^{a}$ Bienal de São Paulo. Acessado em 13 nov. 2019, http://materialeducativo.32bienal.org.br/.
} 
pesquisadora Milene Rodrigues Martins (2016, 9), 5 apresenta as obras de Bené Fonteles, Koo Jeong A e Mariana Castilho Deball. O texto introdutório aborda a cosmologia de uma perspectiva da astronomia, envereda por debates científicos contemporâneos e compreende a cosmologia como uma reflexão filosófica mais ampla sobre a origem do universo. Neste texto, o vocabulário científico divide espaço com temas provenientes do universo místico e religioso, com referências ao xamanismo, alquimia, espiritualidade e magia. Na apresentação da obra de Bené Fonteles, a autora explica:

Pode-se dizer que o artista resolve a forma de suas esculturas, performances e instalações na esfera ritualística, buscando o que chama de lógica transmutadora. Em seus trabalhos, a potencialidade estética está profundamente atrelada à elevação espiritual. (Martins 2016, 9)

O texto postula uma proposta de compreender a relação homem/natureza a partir de princípios que extrapolem os domínios da ciência convencional. Em grande parte das obras a inspiração para esta compreensão é buscada em sociedades e universos conceituais não-ocidentais. Esta inspiração torna-se patente no trabalho de Bené Fonteles, onde a figura do xamã, lider místico indígena é uma referência constante.

Na concepção da Bienal, o tema da relação magia, arte e ciência vem à tona nas articulações estabelecidas entre artistas e os curadores, assim como nos diálogos propostos com o público. Como pode-se ler na descrição da obra Ágora: oca, tapera, terreiro, no site da Bienal:

\begin{abstract}
Dentro do Pavilhão da Bienal, Fonteles propõe uma construção de teto de palha e paredes de taipa, materiais usados em habitações indigenas e caboclas. O título carrega o desejo de interligar vários tempos e conhecimentos, tendo o terreiro como referência a um espaço de celebrações e oferendas. A instalação abriga composições em que são usados materiais orgânicos, resquícios trazidos pelo mar, artefatos tradicionais e objetos coletados por Fonteles durante suas jornadas a diferentes regiões do país. Texturas, sons e cheiros compõem o ambiente, que abriga, em uma programação contínua, trocas entre o artista, músicos, xamãs, educadores e o público. O lugar e as práticas ali desenvolvidas são um convite para que todos atuem na transmutação da realidade e no reencantamento do mundo. ${ }^{6}$
\end{abstract}

Conforme pode-se perceber pelo discurso dos curadores, expresso no catálogo da exposição e nos materiais educativos, a intensão do artista é oferecer ao público a oportunidade de experienciar vivências inspiradas nas cosmovisões indigenas. No interior desta instalação, Fonteles realizou performances com público inspiradas em práticas xamânicas de indigenas brasileiros.

\section{Cobertura midiática da obra de Bené Fonteles}

A matéria publicada pelo jornal Folha de S. Paulo, apresenta a seguinte declaração de Fonteles: "Se hoje o pessoal chama para a bienal é porque eles querem outra coisa. Não é só o artista que estão convidando. Dizem que também sou um xamã"7. O texto jornalístico ressalta as características xamânicas da obra e da trajetória do artista, que justificam ter sido escalado para participar da Bienal.

\footnotetext{
5 Martins, Milene R. 2016. Cosmologia e incerteza. Cadernos educativos da $32^{a}$ Bienal de São Paulo. Acessado em 13 nov. 2019 , http:// materialeducativo.32bienal.org.br.

6 Bienal. 2016b. Catálogo online da $32^{a}$ Bienal de São Paulo. Acessado em 12 jun. 2018, http://www.32bienal.org.br/pt/participants/o/2536. 
Figura 1 - Site Bienal $2019^{8}$

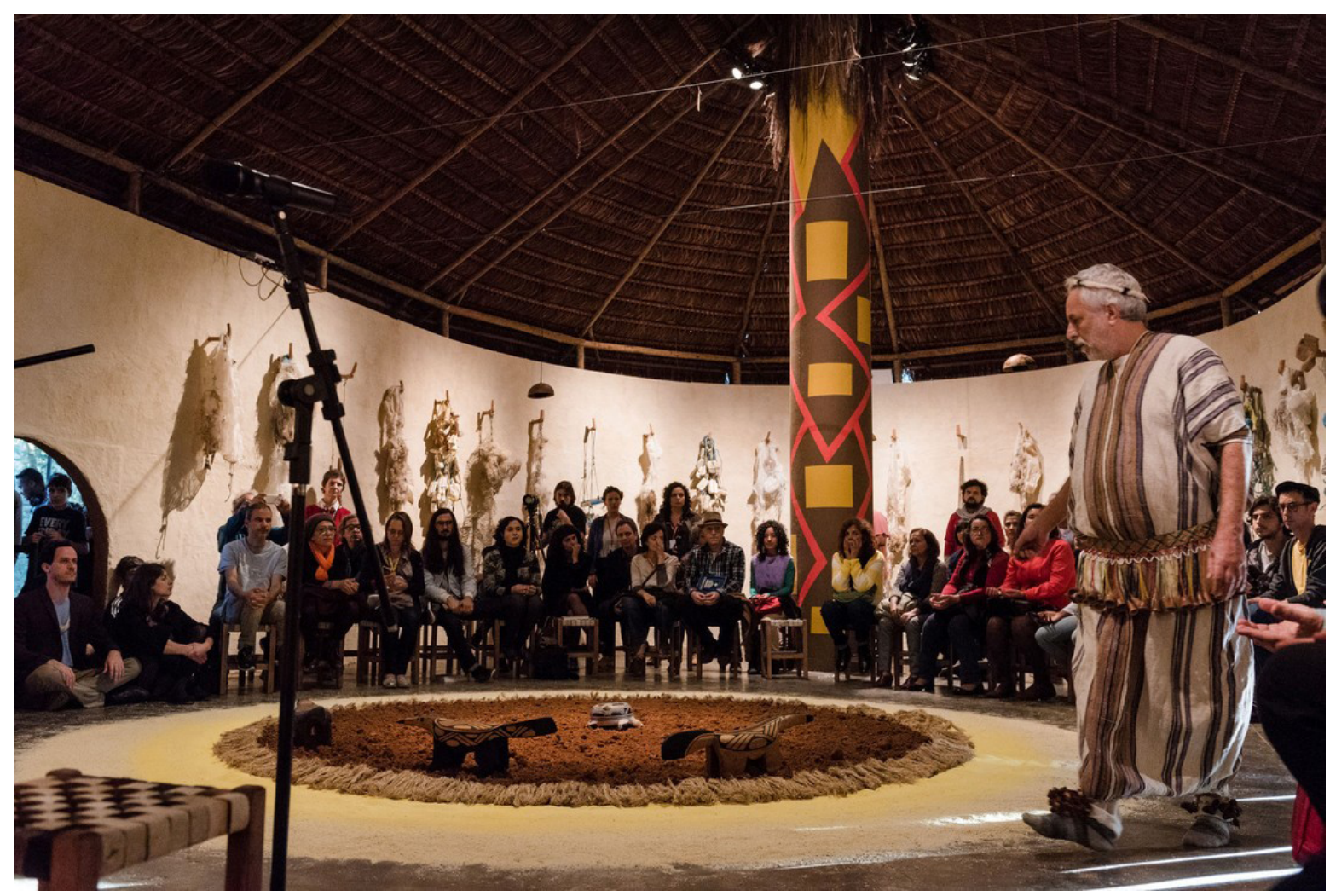

Fonte: Site da 34ª Bienal de São Paulo. Acessado em 25 set. 2019, http://www.bienal.org.br/agenda/2725.

A matéria relata a performance coordenada por Fonteles no Festival da Arte de Bragança Paulista, onde construiu uma oca, que serviu de protótipo para a que foi instalada na Bienal:

\begin{abstract}
"Aqui é a iniciação de tudo", ele diz, do lado de fora da oca na fazenda. "Lá vai ser diferentes porque não pode enfiar nenhum pau no chão nem fazer nada com as colunas. É a mesma história só que a estrutura é toda de taipa. A construção cabocla, que é o cruzamento de branco e de indio, parte da estrutura indigena para fazer as paredes de barro. Dentro da Bienal quero por esta tecnologia indigena em confronto com a arquitetura modernista".9
\end{abstract}

Após a Bienal, o artista seguiu realizando exposições e mostras no Brasil, que atraem atenção da imprensa, que continua referindo-se ao artista a partir de termos relacionados com suas performances xamânicas. A matéria do jornal $O$
Estado do S. Paulo, sobre sua exposição individual realizada em 2018, tem como subtítulo: Guardião das tradições ancestrais, paraense de 65 anos abre mostra composta por uma seleção de obras realizadas entre os anos 1980 a 2000.10

O texto jornalístico inicia apresentando a carreira do artista, onde ressalta que apesar das oportunidades de fazer uma carreira internacional, Fonteles fez uma opção militante por permanecer no Brasil. A matéria destaca o comprometimento do artista com a realidade e com as causas sociais brasileiras e amazônicas, colocando como um mérito sua opção pelo Brasil:

Embora conhecido aqui e fora do Brasil, com suas obras em coleções internacionais (de Yoko Ono ao MoMa, entre outras), o artista paraense Bené Fonteles, 65, mantém cuidadosa distância do mercado. Na $32^{\mathrm{a}}$ Bienal de São Paulo, em 2016, o Museu Reina Sofia, de

8 Fonteles, Bené. Ágora: oca, tapera, terreiro. 2016. Instalação

9 Marti, Silas. 2016. Para ensaiar vivências, Bené Fonteles constrói oca em Bragança Paulista (SP). Folha de S.Paulo. Acessado em 25 set 2019, https://www1.folha.uol.com.br/ilustrada/2016/07/1793633-para-ensaiar-vivencias-bene-fonteles-constroi-oca-em-braganca-paulista-sp.shtml.

10 Gonçalvez Filho, Antonio. 2018. Guardião de tradições ancestrais, Bené Fonteles faz exposição em São Paulo. Estado de S. Paulo, Cultura. Acessado em 25 set 2019, https://cultura.estadao.com.br/noticias/artes,artista-bene-fonteles-faz-exposicao-em-sao-paulo.70002611622. 
Madrid, mostrou interesse em comprar para seu acervo a xamânica oca montada por ele no pavilhão da amostra - Fonteles simplesmente respondeu não à proposta (ibid.).

A obra de Bené Fonteles, apesar de inspirada em temas indígenas e ligados ao xamanismo, não estabelece nenhuma colaboração direta com povos indigenas. Passaremos agora a analisar outro artista brasileiro de destaque que desenvolve estreita colaboração com indígenas na busca de novas ontologias.

\section{Cobertura midiática da obra de Ernesto Neto}

Ernesto Neto é um artista cujo trabalho produzido a partir da colaboração com os índios Huni Kuin ganhou projeção internacional. A partir da convivência com esse povo indígena e do uso ritual da ayahuasca, Neto propõe instalações que se utilizam de padrões geométricos inspirado em grafismos indígenas e cujo universo sensorial remete o expectador à experimentação táctil, visual e olfativa:
As matérias-primas básicas de Ernesto Neto costumam ser tecidos elásticos (que pendem do teto, como gotas); bolinhas de isopor (que preenchem partes deste tecido); e temperos (que conferem odor aos espaços). Com estes elementos, constrói ambientes envolventes que têm aspecto vivo, como amídalas ou visceras. (Goldstein e Labate 2017, 449)

Neto proporciona aos visitantes das suas exposições a possibilidade de participar em rituais com uso de ayahuasca, conduzidos pelos próprios indígenas. Tal aconteceu na exposição Histórias Mestiças realizada no Instituto Tomie Otake, em 2014, em São Paulo, e na exposição Aru Kuxipa | Sagrado Segredo realizada em Veneza em 2015. Em 2017, na Bienal de Veneza, Ernesto Neto representou o Brasil em uma ala da exposição intitulada Pavilhão dos Xamãs, onde também foram celebrados rituais coordenados por indígenas Huni Kuin, que atraíram grande atenção do público e da imprensa.

Figura 2 - Site Bienal 2017 ${ }^{11}$

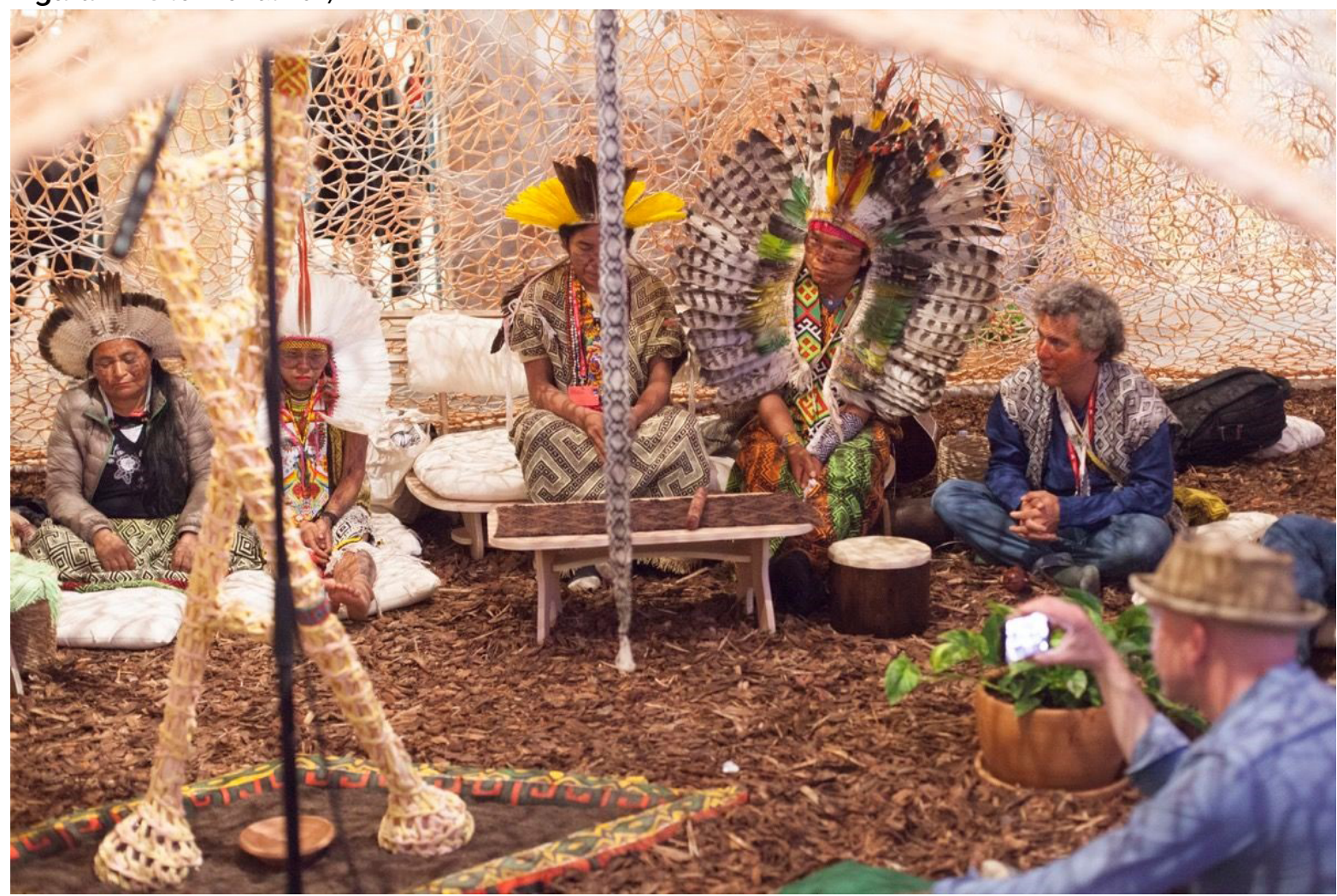

Fonte: Site da 57 Bienal de Venecia 2017. Acessado em 25 set. 2019, https://universes.art/es/bienal-venecia/2017/viva-arte-viva/photos-arsenale-2/ernesto-neto-huni-kuin-2.

11 Neto, Ernesto. Pavilhão dos Xamãs. 2017. Instalação 
O trabalho de Ernesto Neto é constituido por diversas obras, com inspiração amazônica e ecológica. Recentemente, uma exposição retrospectiva do seu trabalho artístico entrou em cartaz em São Paulo. A cobertura midiática da exposição, novamente reitera termos que associam Amazônia e povos indígenas com magia, ecologia e animismo. As matérias jornalísticas destacam a fala do artista:

Segundo Ernesto Neto, é preciso entender o planeta como organismo interdependente, que tem sua fonte de conhecimento nos povos da floresta. "A convivência com os Huni Kuin me trouxe um entendimento profundo da espiritualidade, desta força de continuidade do 'corpo-eu' e do 'corpo-ambiente'. Há muito para descobrir enquanto humanidade: quem somos? Onde estamos? Para onde vamos?", pergunta o artista. $^{12}$

Na cobertura do mesmo site sobre uma outra obra de Neto exposta em Zurique, o texto destaca termos ligados a ecologia, natureza e Amazônia:

O artista contemporâneo Ernesto Neto leva um pouco da Floresta Amazônica para o centro da estação de Zurique, na Suiça. Batizada de Gaia Mother Tree (na tradução livre, seria a Árvoremãe Gaia), a gigantesca instalação surpreende o mais de meio milhão de pessoas que atravessam o local diariamente. A obra convida os passantes para um momento de contemplação e vivência, além também de propor um instante de reflexão sobre a sustentabilidade. ${ }^{13}$

Pode-se ver nesse texto, a ênfase nativista na ideia de que a obra inspirada na floresta amazônica teria algo a contribuir às experiências dos moradores da cidade europeia, por trazer elementos de encantamento e ludicidade que são atribuidos as vivências cotidianas indígenas. Esse é o mesmo tom de uma matéria que discute a expressividade da arte brasileira no mercado de arte europeu. O título da matéria: Por que a arte brasileira faz tanto sucesso na Suiça, já demonstra a abordagem escolhida pela jornalista, que vai destacar na fala dos entrevistados supostos aspectos da especificidade do povo brasileiro que se tornam atraentes para o consumidor de arte europeu. A matéria, da revista Época Negócios, descreve a obra de Ernesto Neto, Grand Mother Tree, instalada na capital da Suiça:

Durante este mês de julho, quem desembarca na estação central de Zurique se depara com uma enorme árvore feita de crochê. A peça, uma escultura interativa do carioca Ernesto Neto, impressiona pela magnitude e traz a Amazônia para o coração da cidade mais movimentada da Suiça, por onde circulam $460 \mathrm{mil}$ pessoas a cada dia. ${ }^{14}$

Depois de explicar a obra e o trabalho de Ernesto Neto, a matéria trata dos números econômicos que movimentam obras de arte brasileiras na Suiça, US\$ 5 milhões, para concluir apontando quais os aspectos da arte brasileira apreciados pelos suiços:

Kono explica que a fascinação suiça por instalações como a árvore gigante se origina da abordagem "democrática" que a arte brasileira propicia. O artista oferece ao público a oportunidade de viver as emoções. Nessa obra, por exemplo, as pessoas são convidadas a utilizar o espaço dentro da escultura livremente para recreação, meditação e relaxamento. "Esse é um espaço público, e essa obra é sobre intimidade", resumiu o criador Ernesto Neto. ${ }^{15}$

Ou seja, a referência à emotividade, misticismo e ao irracional associados à Amazônia e à arte, que se utiliza dela como referência criativa, está novamente presente no texto, como podemos notar no subtítulo da matéria: A arte brasileira é espontânea e democrática.

Nesta matéria ganham destaque alguns antigos estereótipos associados ao Brasil, como a própria noção de cordialidade, já destacada por Sergio Buarque de Hollanda (1995). Em seguida se discutirá como estes discursos se coadunam

\footnotetext{
12 Balva, Cristina. 2019. Retrospectiva de Ernesto Neto leva a Amazônia para a Estação de Zurique na Suiça. CasaCor. Acessado em 25 set 2019, https://casacor.abril.com.br/arte/retrospectiva-de-ernesto-neto-e-a-grande-atracao-da-pinacoteca/.

13 Alcantara, Alex. 2018. Ernesto Neto leva a Amazônia para a Estação de Zurique na Suiça. CasaCor. Acessado em 25 set 2019 , https:// casacor.abril.com.br/arte/ernesto-neto-leva-a-amazonia-para-estacao-de-zurique-na-suica.

14 Wentzel, Marina. 2018. Porque a arte brasileira faz tanto sucesso na Suiça. Época Negócios, 30 jul. 2018. Acessado em 13 nov. 2019, https://epocanegocios.globo.com/Mundo/noticia/2018/07/por-que-arte-brasileira-faz-tanto-sucesso-na-suica.html.

15 Wentzel, Marina. 2018. Porque a arte brasileira faz tanto sucesso na Suiça. Época Negócios, 30 jul. 2018. Acessado em 13 nov. 2019 . https://epocanegocios.globo.com/Mundo/noticia/2018/07/por-que-arte-brasileira-faz-tanto-sucesso-na-suica.html.
} 
com algumas propostas epistemológicas presentes na arte contemporânea.

\section{O lugar da Amazônia: a politização da} alteridade como uma estratégía discursiva

Na cobertura jornalística do trabalho de artistas que fazem referência à Amazônia e aos povos da floresta é possivel identificar referências a estereótipos recorrentes. Estes estereótipos referem-se a um imaginário que percebe estes artistas como representantes bem sucedidos do Brasil e da Amazônia no exterior, o que os tornam destaques nessas exposições.

Outro ponto muito presente no discurso sobre esses artistas é a referência ao misticismo e ao xamanismo. A noção de um xamã como lider espiritual que possui algum conhecimento secreto, passivel de ser repassado para aqueles que o procuram é utilizada de forma recorrente como um marketing pessoal proposto por estes artistas e endossado pela cobertura midiática do seu trabalho. O próprio fato de dois artistas brasileiros terem sido alocados no Pavilhão dos Xamãs na Bienal de Veneza, em 2017, mostra a força deste estereótipo no que diz respeito a arte nacional. ${ }^{16}$

A proposta estética destes artistas também vai ao encontro a esse imaginário, quando operam por meio de grandes instalações de caráter imersivo, nas quais o visitante é convidado a participar e ingressar em um cenário onde supostamente se abririam para ele novas compreensões de mundo. Além disso, ambos artistas possuem comportamento engajado em defesa da Amazônia e dos povos indigenas, o que seria coerente com seu trabalho estético. Esse conjunto de fatores costuma ser noticiado pela mídia de maneira positiva e destacada. Constrói-se assim uma equação de sucesso no discurso midiático com a associação entre ecologia, ativismo e misticismo. Essa equação sugere ao leitor que a superação dos problemas ecológicos poderia vir através de uma redescoberta de cosmologias, experiências misticas e estéticas inspiradas nos povos da floresta.

As propostas artísticas que buscam uma intervenção na sociedade a partir de um repensar da relação entre homem e natureza, pretendem realizar a desconstrução do discurso científico racionalista cartesiano como a única possibilidade de reflexão sobre a sociedade e o cosmos. Como podemos ler nos Cadernos Educativos da $32^{\mathrm{a}}$ Bienal de Arte São Paulo:

Cotidianamente, a educação acadêmica reconhece, em suas salas de aula, que toda certeza propagada pela ciência no século 20 contém uma ampla gama de incertezas, que aparecem em novos questionamentos derivados de hipóteses e descobertas (Volz e Prates 2016, 3).17

Neste sentido, os "artistas xamãs" e as suas obras propõem pensar a relação com a natureza a partir de um paradigma animista, no qual seres humanos, animais, vegetais ou seres inanimados teriam o mesmo estatuto ontológico. Inspirados na repercussão de conceitos de autores como Eduardo Viveiros de Castro (2002) e suas análises sobre o perspectivismo ameríndio e em Boaventura de Sousa Santos (2007), que discute sobre a ecologia de saberes, surge toda uma prática artística e curatorial voltada para levar o espectador a pensar sua relação com a natureza para além das categorias de sujeito e objeto. Pode-se observar a influência dessas concepções na arte brasileira contemporânea no vídeo ${ }^{18}$ da pesquisadora Bia Machado veiculado no Youtube e na palestra ${ }^{19}$

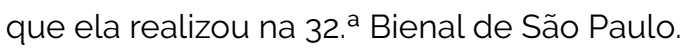

O perspectivismo é uma abordagem conceitual proposta pelo antropólogo Eduardo Viveiros de Castro, na qual compreende-se a ontologia indígena como uma forma de ver o mundo em que a cultura mantém-se constante enquanto a natureza é uma variável; ou seja, nas ideias de Viveiros de Castro, os indigenas acreditariam que outros seres da natureza, como plantas e animais, também

\footnotetext{
16 O outro artista foi Ayrson Heráclito cuja obra inspira-se nas religiões afro-brasileiras.

17 Volz, Jochen e Valquiria Prates. 2016. Incerteza viva: processos artísticos e pedagógicos da $32^{\text {a }}$ Bienal de São Paulo. Cadernos Educativos da $32^{a}$ Bienal de São Paulo. Acessado em 13 nov. 2019, http://materialeducativo.32bienal.org.br.

18 Machado, Bia. 2016a. Bia Machado e o Mundo Encantado. Flow desenvolvimento sustentável e consciente. Youtube. Acessado em 25 set. 2019, https://www.youtube.com/watch?v=y98ELRUu4A8.

19 Machado, Bia. 2016b. Palestra 32a Bienal de São Paulo. Youtube. Acessado em 25 set. 2019, https://www.youtube.com/watch?v=bivvCukGDTw.
} 
são dotados de cultura (Viveiros de Castro 2002). Segundo ele, os indigenas possuem a capacidade de ver o mundo sob diversas perspectivas, adotadas por animais, plantas e seres espirituais, que variam de acordo com o posicionamento destes seres no sistema cosmológico.

As proposições teóricas baseadas no perspectivismo despertaram interesse de profissionais ligados ao mundo da arte. Nas últimas décadas têm despontado no cenário da arte contemporânea diversos artistas e curadores cujas propostas inspiram-se em maior ou menor grau nesse modelo de entendimento do mundo.

Entretanto, esse modelo corre risco de cair nas armadilhas da idealização do outro, notadas por Hall Foster. O autor discorre sobre o deslocamento do lugar do outro na arte do século 20 , onde paulatinamente o lugar do oprimido, antes ocupado pela classe operária, vem sendo preenchido por outras formas de alteridade, definidas pela cultura, não mais pela desigualdade econômica. Nesse processo, o artista incorpora e busca inspiração em métodos e práticas da antropologia, como a etnografia:

O paradigma do etnógrafo não logra refletir sobre seu pressuposto realista: que o outro, aqui o pós-colonial, lá o proletário, está de alguma forma na realidade, na verdade, não na ideologia, porque ele é socialmente oprimido, politicamente transformador e/ou materialmente produtivo (Foster 2005, 162).

Esse olhar redutor sobre a alteridade está presente no próprio perspectivismo ameríndio enquanto abordagem teórica sobre as culturas indígenas. Segundo aponta a antropóloga Alcida Rita Ramos (2012), o perspectivismo ameríndio enquanto enfoque teórico leva a uma excessiva homogeneização do pensamento indigena, reduzindo-o a uma visão simplista e estereotipada:

The Indians thus portrayed, regardless of where they are in the Amazon, what their linguistic affiliation is, and which historical paths they have trodden, differ very little from each other. Perhaps the model's excessive generality and its prêt-à-porter character render it easily applicable even when it is not quite appropriate (Ramos 2012, 482).
Se o perspectivismo aplicado à diversidade cultural indigena se torna um modelo redutor e simplista, a arte inspirada no xamanismo amerindio também incorre em excessiva homogeneização. Este tipo de trabalho geralmente consiste em um conjunto de objetos dispostos em instalações, que buscam sugerir para o expectador a experiência de estar em um ambiente povoado por objetos retirados de uma outra cultura. Os artefatos indigenas, geralmente observados apenas em coleções etnográficas, passam a ser admirados e experimentados como objetos artísticos em exposições de arte contemporânea.

No caso das referidas obras de Fonteles e Neto, vamos encontrar instalações compostas por cocares e outros objetos indigenas, misturados com objetos confeccionados com palha e cerâmica. Instalações que se transformam em palco para rituais de inspiração religiosa ou xamânica, como é o caso da obra de Ernesto Neto que se utilizou do ritual da ayahuasca. A ênfase em processos e mediações, assim como na criação coletiva reforça um discurso artístico em que o público deveria ser levado a envolver-se em práticas de ativismo que extrapolam a contemplação estética. Um exemplo destes processos pode ser encontrado na vasta quantidade de materiais educativos produzidos para a $32^{a}$ Bienal de São Paulo e nos eventos paralelos desenvolvidos pelos curadores. A proposta é que uma exposição de arte se transforme em um eixo de um elaborado conjunto de ações de ativismo político.

Propõe-se que o espectador aprenda a pensar e a ver o mundo da perspectiva indígena (ou do xamã), para que possa assim estabelecer novas relações com o meio ambiente. Ao adotar a maneira de ver do xamã, o sujeito ocidental teria a possibilidade de superar a crise ecológica, pois, supostamente passaria a estabelecer um novo tipo de relação, mais respeitosa e harmônica, com a natureza.

\section{Da representação artística ao discurso da mídia: alguns pontos de encontro}

Ao realizar a cobertura jornalística de exposições e obras de arte baseadas nestes pressupostos, a mídia tende a aceitar de maneira 
acrítica o discurso de união com o outro, onde a simples representação artística da alteridade é vista como positiva por proporcionar ao público essa fusão com o universo indígena. Os artistas xamãs são vistos como visionários e defensores da cultura amazônica, assim como legitimos porta-vozes da cultura brasileira no exterior. 0 que retoma a já conhecida visão de Brasil e de Amazônia associados à alegria, à simplicidade, à natureza e ao primitivo.

Observa-se que a midia reitera as propostas dos artistas, as quais associam e resumem a Amazônia aos povos indígenas. Frases como "a fascinação suiça por instalações como a árvore gigante se origina da abordagem 'democrática' que a arte brasileira propicia" 20 e "o artista [...] leva um pouco da Floresta Amazônica para o centro da estação de Zurique, na Suiça, ${ }^{21}$ são usadas com intuito de reforçar a ideia de que as representações contidas nas obras de Neto são legítimas enquanto representações reais da Amazônia e do Brasil. Os textos jornalísticos também reforçam os estereótipos de xamã como um ser humano portador de conhecimentos profundos, como é o caso do título Guardião das tradições ancestrais da reportagem do Estado de São Paulo. ${ }^{12}$ Além de associar Fonteles à figura do xamã, a mesma matéria também legitima o engajamento de sua arte a partir das escolhas de vida do artista, que destaca como sendo sua militância.

Poderiamos nos questionar se os discursos midiáticos apresentam uma invenção própria na medida em que se referem às obras como representações de uma Amazônia vinculada a um sentimento ecológico que é mágico e espiritual. Porém, notamos que as próprias obras citadas também trazem essa ligação com referenciais místicos e religiosos. O termo "xamã" ("Pavilhão dos xamãs") e o uso de adereços indígenas como cocares e elementos rituais como a ayahuasca, presentes na obra de Fonteles e de Neto, compõem um contexto imaginário sobre o que são os povos da Amazônia que a mídia não se nega a reproduzir.
Nesse sentido, expressão artística e discurso midiático unem-se na ratificação do estereótipo dos indigenas como bons selvagens, na perspectiva do termo cunhado por Jean-Jacques Rousseau, o que não contribui para a desconstrução do padrão de exotismo comumente referido aos povos amazônicos. O que vemos portanto é uma alteridade idealizada, onde o modo de vida indígena apresenta-se como um modelo a ser seguido que traria soluções para as crises paradigmáticas do Ocidente.

\section{Considerações finails}

Esta pesquisa exploratória pretendeu analisar alguns aspectos da cobertura midiática sobre a representação da Amazônia no trabalho de artistas que envolve o diálogo e a defesa dos povos indígenas brasileiros. Para tanto foi escolhida a obra de Ernesto Neto e Bené Fonteles, dois artistas visuais brasileiros cujas obras ganharam destaque nacional e internacional pelo diálogo estabelecido com as culturas indígenas e com a temática da Amazônia.

A partir desta análise é possivel concluir que os temas relacionados à Amazônia e aos povos indígenas que adquirem destaque na mídia frequentemente seguem relacionados com o imaginário do primitivo e do exótico, o que neste caso é reificado pelo próprio formato da obra dos artistas, que se afinam com uma recente retomada da valorização destes temas na arte contemporânea.

Surge também com destaque nesta equação o imaginário do xamã, líder indigena considerado capaz de estabelecer pontes com o sobrenatural, que é visto como um mediador da experiência estética proposta pelos artistas. Ao se identificarem com os xamãs, como fica explicitado, entre outras formas, no termo "Pavilhão do Xamãs", estes artistas propõem fornecer ao expectador uma nova forma de compreensão do mundo a partir do diálogo com as cosmovisões indigenas e amazônicas. Estas novas cosmovisões e

\footnotetext{
20 Wentzel, Marina. 2018. Porque a arte brasileira faz tanto sucesso na Suiça. Época Negócios. 25 set 2019, https://epocanegocios.globo. com/Mundo/noticia/2018/07/por-que-arte-brasileira-faz-tanto-sucesso-na-suica.html.

${ }_{21}$ Alcantara, Alex. 2018. Ernesto Neto leva a Amazônia para a estação de Zurique na Suiça. CasaCor. 25 set 2019 , https://casacor.abril. com.br/arte/ernesto-neto-leva-a-amazonia-para-estacao-de-zurique-na-suica.
} 
experiências frequentemente estão associadas a questão da espiritualidade.

Os artistas apresentam-se ao público como xamãs e pretendem proporcionar um diálogo privilegiado com a alteridade para aqueles que apreciam suas obras. Por outro lado, esta alteridade representada pelos artistas e reforçada pelo discurso da mídia segue reproduzindo estereótipos e associações dos povos indígenas e da Amazônia à simplicidade e ao exotismo.

A proliferação das práticas de arte xamânica em grandes exposições ressalta a relevância do tema para a atualidade e a permanente necessidade das instituições culturais do Ocidente de projetarem a solução de seus problemas políticos e éticos em uma alteridade idealizada. Por outro lado, a análise destas práticas artísticas pode lançar luz sobre problemas contemporâneos como o relativismo e o lugar da arte na promoção de reflexões éticas, estéticas e políticas, que tanto são reforçados pelos discursos midiáticos.

\section{Referências}

Bishop, Claire. 2012. Artificial hells: participatory arts and the politics of spectatorship. New York, London: Verso.

Foster, Hal. 2005. O artista como etnógrafo. In Deslocalizar a Europa: antropologia, arte, literatura e história na pós-colonialidade, organizado por Manuela Ribeiro Sanches, 158-185. Lisboa, Cotovia.

Goldstein, Ilana e Beatriz Caiuby Labate. 2017. Encontros artísticos e ayahuasqueiros: reflexões sobre a colaboração entre Ernesto Neto e os Huni Kuin. Mana 23 (3): 437471. https://doi.org/10.1590/1678-49442017v23n3p437.

Holanda, Sérgio B. 1995. Raízes do Brasil. 26 ed. São Paulo: Companhia das Letras.

Linhares, Claudia Rodriguez-Ponga. 2018. Pequeno tratado sobre arte e magia. Tese em Artes Visuais, USP, São Paulo.

Ramos, Alcida Rita. 2012. The politics of perspectivism. Annual Review of Anthropology 41: 481- 494. https://doi. org/10.1146/annurev-anthro-092611-145950.

Sant'anna, Sabrina Marques Parracho, Guilherme Marcondes e Ana Carolina Freire Accorsi Miranda. 2017. Arte e política: a consolidação da arte como agente na esfera pública. Sociologia e Antropologia 7 (3): 825-849. https://doi.org/10.1590/2238-38752017v737.

Santos, Boaventura de Sousa. 2007. Para além do pensamento abissal: das linhas globais a uma ecologia de saberes. Novos Estudos Cebrap 79: 71-94. https://doi. org/10.1590/S0101-33002007000300004.
Viveiros de Castro, Eduardo. 2002. A inconstância da alma selvagem. São Paulo: Cosaf Naif.

\section{Daniela Cordovil}

Doutora em Antropologia pela Universidade de Brasilia (UnB), Brasilia, DF, Brasil. Professora da Universidade do Estado do Pará (Uepa), Belém, PA, Brasil. Investigadora da Universidade Nova de Lisboa, Lisboa, Portugal, com apoio da Fundação para Ciência e Tecnologia (FCT) de Portugal. 